ISAHPArticle: A Style Guide for Paper Proposals To Be Submitted to the International Symposium of the Analytic Hierarchy Process 2016, London, U.K.

\title{
COMPARATIVE ANALYSIS OF AHP AND FUZZY AHP IN SUPPLIER SELECTION PROBLEM
}

\author{
Ririn Diar Astanti ${ }^{1}$, The Jin $\mathbf{A i}^{2}$, Stephanie Eka Mbolla ${ }^{3}$ \\ Department of Industrial Engineering, Universitas Atma Jaya Yogyakarta, Yogyakarta, Indonesia \\ email:ririn@mail.uajy.ac.id ${ }^{1}$; jinai@mail.uajy.ac.id ${ }^{2}$; imbolla@yahoo.com ${ }^{3}$
}

\begin{abstract}
Appropriate supplier can lead the company to reach its competitive advantage. Many researchers have been conducting research in supplier selection problem using various multi-criteria decision making methods, including the Analytical Hierarchy Process (AHP) and its variation, such as Fuzzy AHP (FAHP). The research in this paper is trying to apply both AHP and FAHP in a glove manufacturer in order to see the role of the expert to the result of both methods. Four experts who are the staff in that company that have been working for 12-16 years are involved to see if FAHP is still needed. The FAHP method in this paper is based on the FAHP model developed by Chang (1996).
\end{abstract}

Keywords: supplier selection problem, priority, AHP, Fuzzy AHP

\section{Introduction}

To achieve the competitive advantage a good supplier that are able to deliver the raw material in the right quantity, at the right time and at the right quality is needed. The research in this paper was conducted in a glove manufacturer. Supplier selection problem is considered as multi criteria decision-making problem. One of the famous methods that has been used is AHP including its variation such as FAHP. However, the used of FAHP require more complex computation rather than the use of AHP.

\section{Literature Review}

Numerous researches have been conducted dealing with supplier selection process. Sometimes the company has to consider both quantitative and qualitative criteria. In that case, AHP method developed by Saaty (1980) is a powerful tool. There exist a criterion we found in our study that has not discussed yet in the previous work which is percentage of quality reduction. Kabir and Hasin (2011) conducted comparative analysis between AHP and FAHP, however the role of the expert to the result of AHP and FAHP which will be the focus of the research in this paper, was not discussed yet in the previous work.

\section{Hypotheses/Objectives}

The research in this paper is trying to observe the role of the expert to the result of AHP and FAHP. The hypothesis is that if the expert is someone who has excellent knowledge and expertise related to the problem he/she is facing, then AHP alone is more than enough to be used as a tools for decision making.

\section{Research Design/Methodology}


The model we developed based on the pool of experts and secondary sources. Secondary sources was used to confirm the criteria that the company used for supplier selection with what other companies had been done. Four experts were involved in this study. They have been working for a this company for 12-16 years. Geometric mean is used to aggregate the opinion from those experts. To reduce the inconsistency when structuring the problem we are trying to build the structure in such a way that in each level at most 5 elements will be pair-wise compared.

\section{Data/Model Analysis}

The decision hierarchy of the supplier selection problem is formulated as follow:

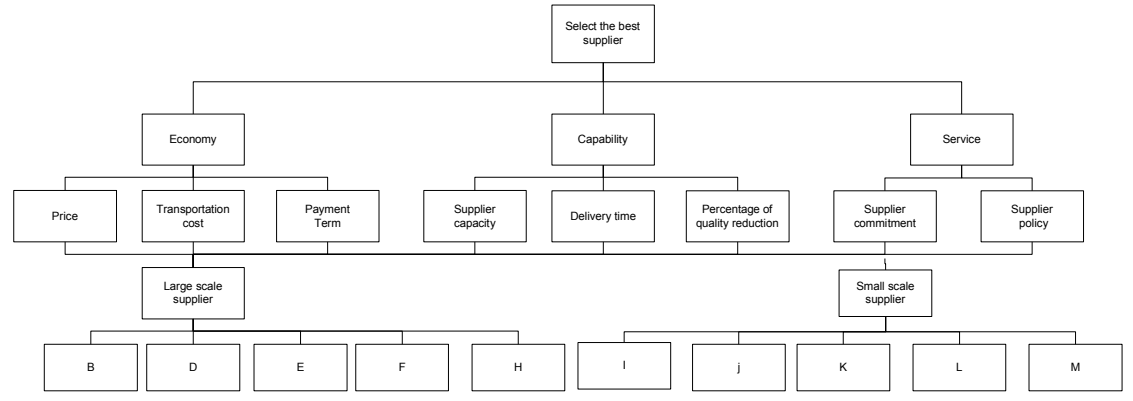

Finally, the priority rank of supplier resulted from both methods are as follows:

AHP : D,B,H,I,J,K,M,L,F,E, FAHP : D,B,H,I,K,J,M,L,E,F

\section{Limitations}

The FAHP method used is this study is based on the extent analysis method provided by Chang (1996) which has been criticized by Wang (2008). Therefore in order to strengthen the result from this paper, further analysis will be conducted by applying other FAHP method such as Wang (2008) and fuzzy logarithmic least squares method (LLSM).

\section{Conclusions}

The contribution of the research in this paper are 1)based on the study we can conclude that if the expert is someone who has excellent knowledge about the problem i.e. some who has been working in the company for more than 12 years, then the result from AHP 
ISAHPArticle: A Style Guide for Paper Proposals To Be Submitted to the International Symposium on the Analytic Hierarchy Process 2016, London, U.K.

and FAHP do not have any differences; 2) in the of supplier selection model we found once criteria that has been discussed yet in the literature review which is percentage of quality reduction.

\section{Key References}

Saaty, T. L. (1980). The Analytic hierarchy process. New York, NY: McGraw-Hill

Chang, D. Y. (1996). Applications of the extent analysis method on fuzzy AHP. European journal of operational research, 95(3), 649-655.

Wang, Y. M., Luo, Y., \& Hua, Z. (2008). On the extent analysis method for fuzzy AHP and its applications. European Journal of Operational Research,186(2), 735-747.

Kabir, G., \& Hasin, M. A. A. (2011). Comparative analysis of AHP and Fuzzy AHP models for multicriteria inventory classification. International Journal of Fuzzy Logic Systems, 1(1), 1-16. 